The submitted manuscript has been authored by a contractor of the U.S. Government under contract No, W-31-109-ENG-38. Accordingly, the U.S. Government retains a nonexclusive, royalty-free license to publish or reproduce the published form of this contribution, or allow others to do so, for U, S. Government purposes.

ANL/ASDICP- 85013

\title{
Effects of Vertical Aperture on Beam Lifetime at the Advanced Photon Source (APS) Storage Ring*
}

\author{
Hana M. Bizek \\ Advanced Photon Source, Argonne National Laboratory \\ 9700 South Cass Avenue, Argonne, Illinois 60439 USA
}

\section{Abstract}

When a positron's energy deviation $\delta \mathrm{E} / \mathrm{E}$ exceeds the $\mathrm{rf}$ acceptance, or when it receives an angular kick for the betatron motion that exceeds some limiting admittance, the positron will be lost. The main contributions to the total beam lifetime come from single Coulomb and Touschek scattering. In this report we investigate the dependence of the residual gas pressure and the vertical aperture of the Advanced Photon Source storage ring on the total beam lifetime. We present results of calculating the total beam lifetime as a function of vertical aperture for varying average ring pressure, beam current, and coupling coefficient.

\section{INTRODUCTION}

The vertical aperture and pressure enter the lifetime calculation through the single Coulomb scattering. In particular, the variation in vertical aperture is due to elastic scattering on nucleii. The Touschek lifetime numbers do not vary with vertical aperture and are read from the table in Ref. [1]. The total beam lifetime is calculated and plotted as a function of the vertical aperture.

The so-called SPEAR scaling calculation is also included. Experimental observations [2] at the SPEAR storage ring seem to suggest that, for short bunches with rms bunch length $\sigma_{l}$ smaller than the beam pipe radius $b$, the effective longitudinal broadband impedance seen by the beam at frequencies beyond $\omega_{c}=c / b$ ( $c$ being the speed of light) is scaled down by a factor of $\left(\sigma_{l} / b\right)^{1.68}$. This phenomenological power law is referred to as the "SPEAR scaling law."

\section{Method of Calculation}

The single Coulomb scattering lifetime for a pressure of $1 \mathrm{nTorr}, \mathrm{T}$, is calculated for a range of vertical apertures. Included are elastic and inelastic scattering on nucleii and electrons. The vertical aperture is taken from $1 \mathrm{~mm}$ to $20 \mathrm{~mm}$, in 1 -mm increments. The highest value of the vertical aperture corresponds to the aperture in the insertion straight sections. The vertical aperture values and the corresponding single-Coulomb scattering lifetime values are used to obtain the singleCoulomb scattering lifetime as a function of the assumed pressure from the formula

$$
\tau_{\text {gas }}=\frac{T}{P}
$$

\footnotetext{
* Work supported by the U.S. Department of Energy, Office of Basic Energy Sciences, under Contract No. W-31-109-ENG-38.
}

where $\mathrm{P}$ is the assumed pressure in nTorr. The single-Coulomb scattering lifetime and Touschek lifetime are inserted into the following equation

$$
\frac{1}{\tau_{\text {total }}}=\frac{1}{\tau_{\text {gas }}}+\frac{1}{\tau_{\text {Touschek }}} .
$$

in order to obtain the total beam lifetime.

The Touschek lifetime is calculated for the APS storage ring, by use of the code ZAP [3]. For the SPEAR scaling calculations, one needs to find the $\mathrm{ms}$ value of the lenghtened bunch, $\sigma_{l}$, and its corresponding rms momentum spread, $\sigma_{\mathrm{p}}$. Once these numbers are obtained from Option 2 of the ZAP code, they are input into the Touschek scattering routine of ZAP. The results are used in the present work.

In each case, the calculated rms minimum bunch length $\sigma_{l}$ is $0.58 \mathrm{~cm}$ and the corresponding rms momentum spread $\sigma_{\mathrm{p}}$ is $0.96 \times 10^{-3}$. In the case of SPEAR scaling, $\sigma_{l}$ and $\sigma_{\mathrm{p}}$ increase, respectively, to $0.89 \mathrm{~cm}$ and $1.48 \times 10^{-3}$ for $5.22 \mathrm{~mA}$ current, and, respectively, to $1.51 \mathrm{~cm}$ and $2.50 \times 10^{-3}$ for $10.44 \mathrm{~mA}$ current.

\section{ANALYSIS OF RESULTS}

Each plot shows the total beam lifetime, as a function of vertical aperture, for pressures of $1 \mathrm{nTorr}, 2 \mathrm{nTorr}, 3 \mathrm{nTorr}$, and $4 \mathrm{nTorr}$; for currents of $1 \mathrm{~mA}, 5.22 \mathrm{~mA}$, and $10.44 \mathrm{~mA}$; and for $10 \%$ and $1 \%$ coupling. The total beam lifetime for $10.44-\mathrm{mA}$ current and $1 \%$ coupling is not shown. In this case, the current is too high and the coupling too low to obtain interesting results. The bucket height is assumed to be $\pm 2 \%$. As may be seen in Figs. 1 through 5, the beam lifetime decreases with increasing current and decreasing coupling. In the case of SPEAR scaling, holding the coupling fixed and increasing the current will not appreciably change the lifetime. This may be seen by comparing Fig. 6 with Fig. 8 and Fig. 7 with Fig. 9 .

Each of these graphs also shows a vertical bar, at the total beam lifetime of 10 hours. This is the minimum allowed lifetime for optimum APS storage-ring operation. Clearly, lifetimes below 10 hours for given vertical apertures are too low. Such vertical apertures are to be avoided. Therefore, this method may predict what kinds of bunches may be sustained at what apertures by estimating the aperture for which a given bunch will operate at exactly 10 hours. For the APS storage ring we consider three phases [4]: the commissioning phase, for which the vertical aperture is $40.7 \mathrm{~mm}$, Phase I, for which the vertical aperture is $12 \mathrm{~mm}$, and Phase II, for which the vertical aperture is $8 \mathrm{~mm}$. According to the APS list of parame- 


\section{DISCLAIMER}

This report was prepared as an account of work sponsored by an agency of the United States Government. Neither the United States Government nor any agency thereof, nor any of their employees, makes any warranty, express or implied, or assumes any legal liability or responsibility for the accuracy, completeness, or usefulness of any information, apparatus, product, or process disclosed, or represents that its use would not infringe privately owned rights. Reference herein to any specific commercial product, process, or service by trade name, trademark, manufacturer, or otherwise does not necessarily constitute or imply its endorsement, recommendation, or favoring by the United States Government or any agency thereof. The views and opinions of authors expressed herein do not necessarily state or reflect those of the United States Government or any agency thereof. 


\section{DISCLAIMER}

Portions of this document may be illegible in electronic image products. Images are produced from the best available original document. 
ters [5], the maximum circulating current for a single bunch is $5 \mathrm{~mA}$.

From Figs. $1-9$ it is immediately seen that a $0.58-\mathrm{cm}$ bunch will not be sustained under 4-nTorr pressure at all, and a $0.58-\mathrm{cm}, 5-\mathrm{mA}$ bunch cannot be sustained under a pressure of 3 nTorr either (Figs. 3 and 4). For SPEAR scaling, both 0.89$\mathrm{cm}$ and $1.51-\mathrm{cm}$ bunches having $10 \%$ coupling can be sustained under 3-nTorr pressure in the insertion straight sections (Figs. 6 and 8), while the $0.89-\mathrm{cm}$ bunch with $10 \%$ coupling can also be sustained under this pressure in Phase I (Fig. 6).

For the pressures of 1 nTorr and 2 nTorr and $10 \%$ coupling, the $0.58-\mathrm{cm}$ bunches, as well as the SPEAR-scaled 0.89$\mathrm{cm}$ and $1.51-\mathrm{cm}$ bunches, are sustained for vertical apertures of all three phases. Moreover, for the lowest pressure (1 nTorr), only the $0.58-\mathrm{cm}$ bunches with $5-\mathrm{mA}$ current and $1 \%$ coupling are not șustained (Fig. 4).

As can be expected, the $0.58-\mathrm{cm}$ bunches with the best lifetimes are those with $1-\mathrm{mA}$ current and $10 \%$ coupling. As Fig. 1 shows, they can be sustained in the ring environment of 1-, 2- and 3-nTorr pressure for all three phases. Figure 2 shows that the 1-mA current bunches with $1 \%$ coupling also do well; however, at $3 \mathrm{nTorr}$ they cannot be sustained in Phase II. On the other hand, the $0.58-\mathrm{cm}, 10-\mathrm{mA}$ bunches do rather poorly. From Fig. 5 it is seen that only bunches having $10 \%$ coupling are sustained at 1-nTorr pressure. Longer bunches stand a better chance under these conditions.

\section{ACKNOWLEDGEMENT}

We would like to acknowledge Drs. Edwin A. Crosbie amd Glenn Decker for continued assistance in this work. Drs. Michael Borland and Louis Emery provided assistance with ZAP.

\section{REFERENCES}

[1] Bizek, Hana M., private communication.

[2] Chao, A. W., "Coherent Instabilities of a Relativistic Bunched Beam," Physics of High Energy Particle Accelerators, SLAC Summer School 1982, AIP Conf. Proc. No. 105,1983, p. 353.

[3] Zisman, M. S., Chattopadhya, S., Bisognano, J. J., "ZAP User's Manual," LBL-21270, December 1986.

[4] "7-GeV Advanced Photon Source Conceptual Design Report," ANL-87-15, April 1987.

[5] Ibid, Appendix A.

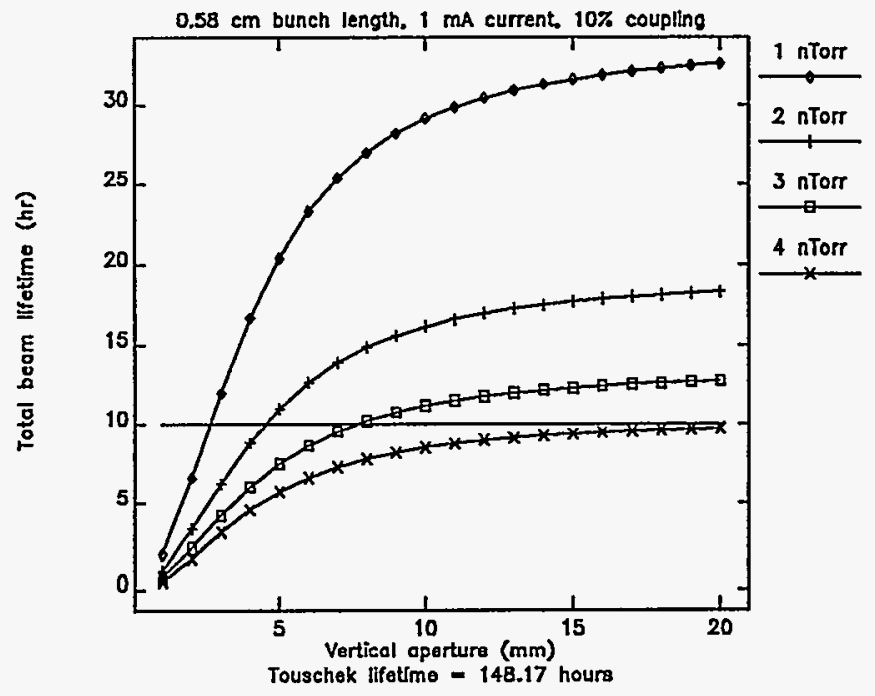

Figure 1

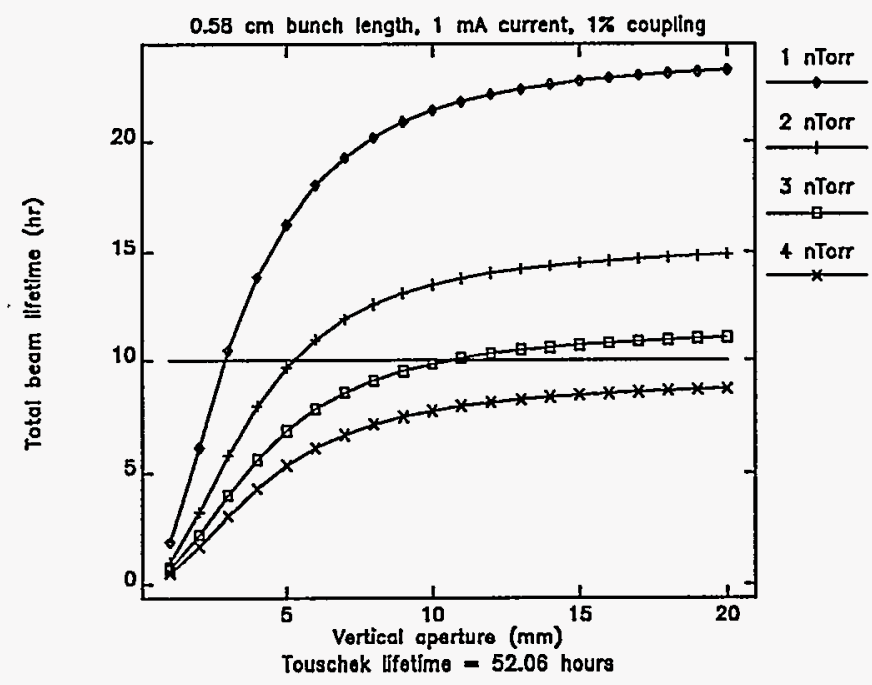

Figure 2

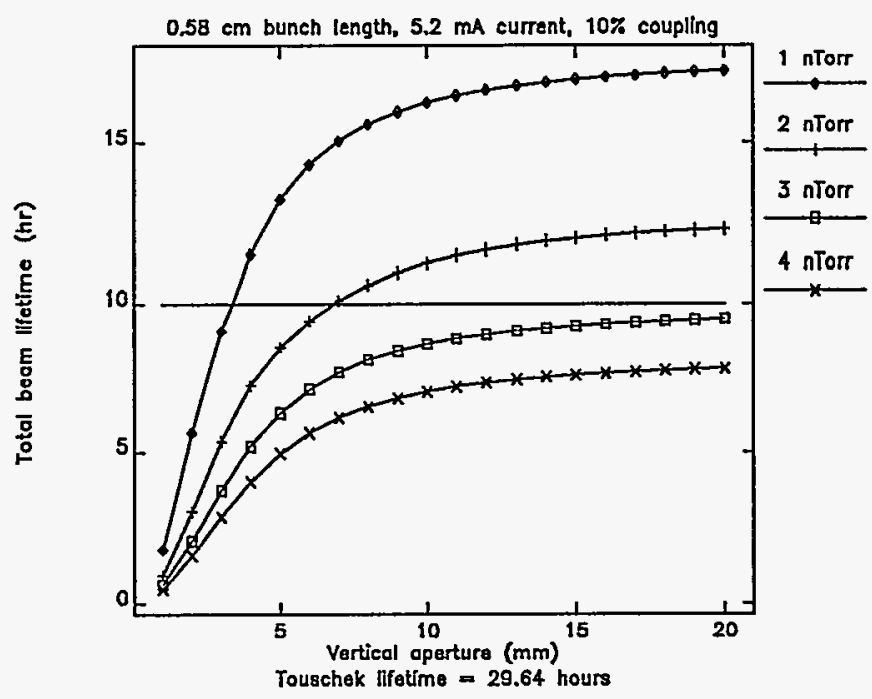

Figure 3 


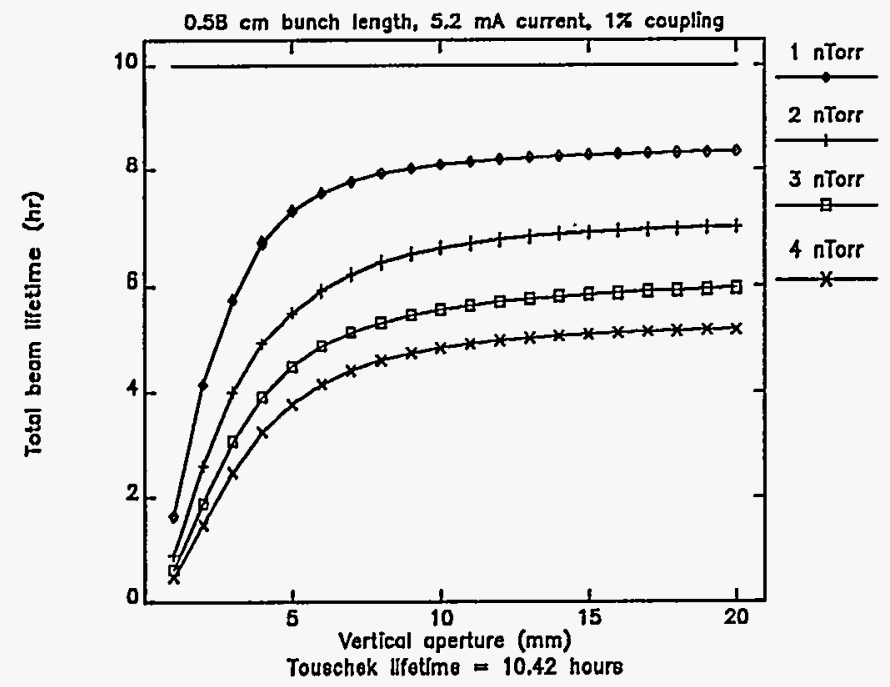

Figure 4

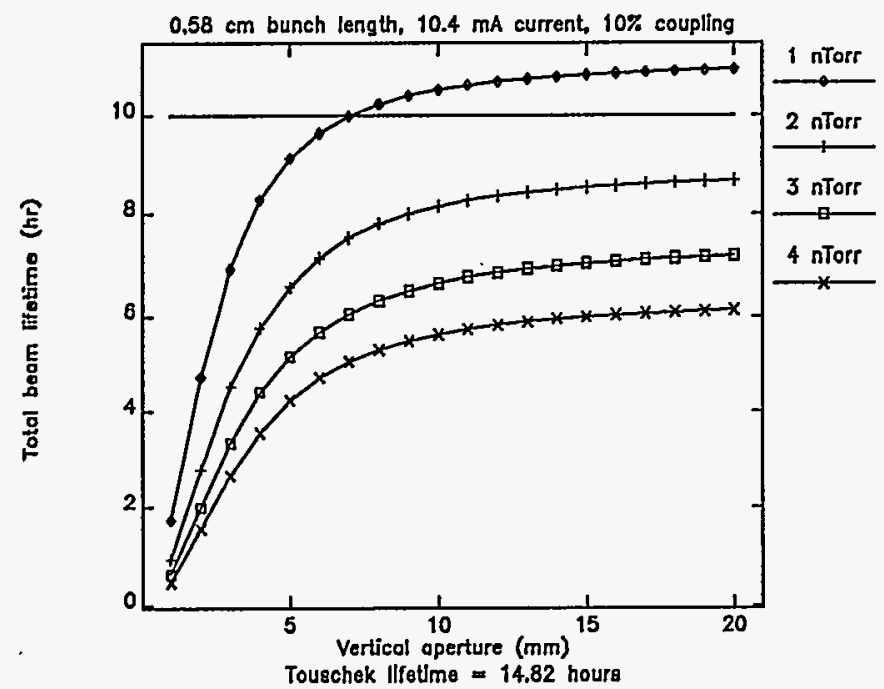

Figure 5

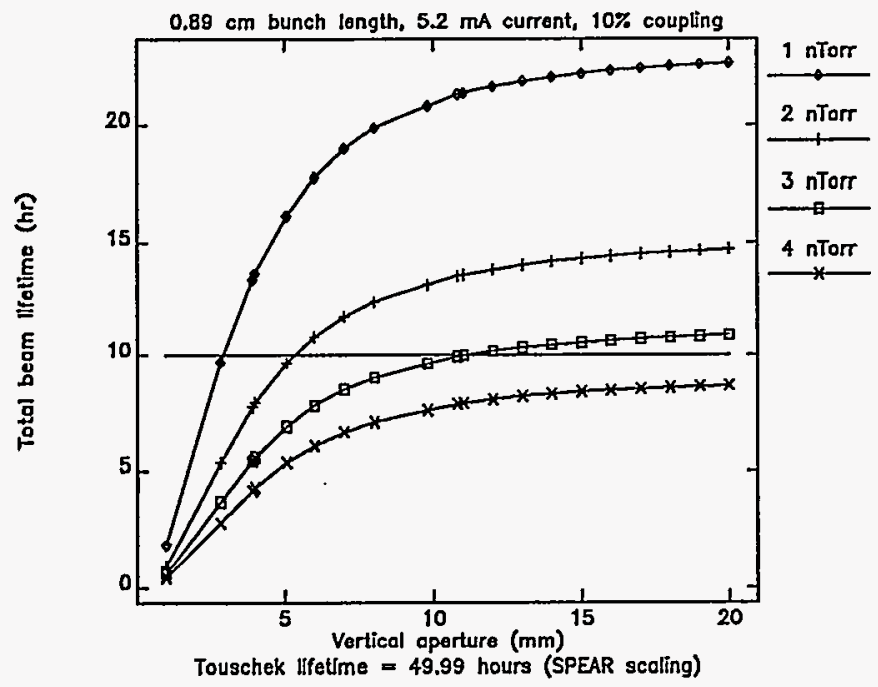

Figure 6
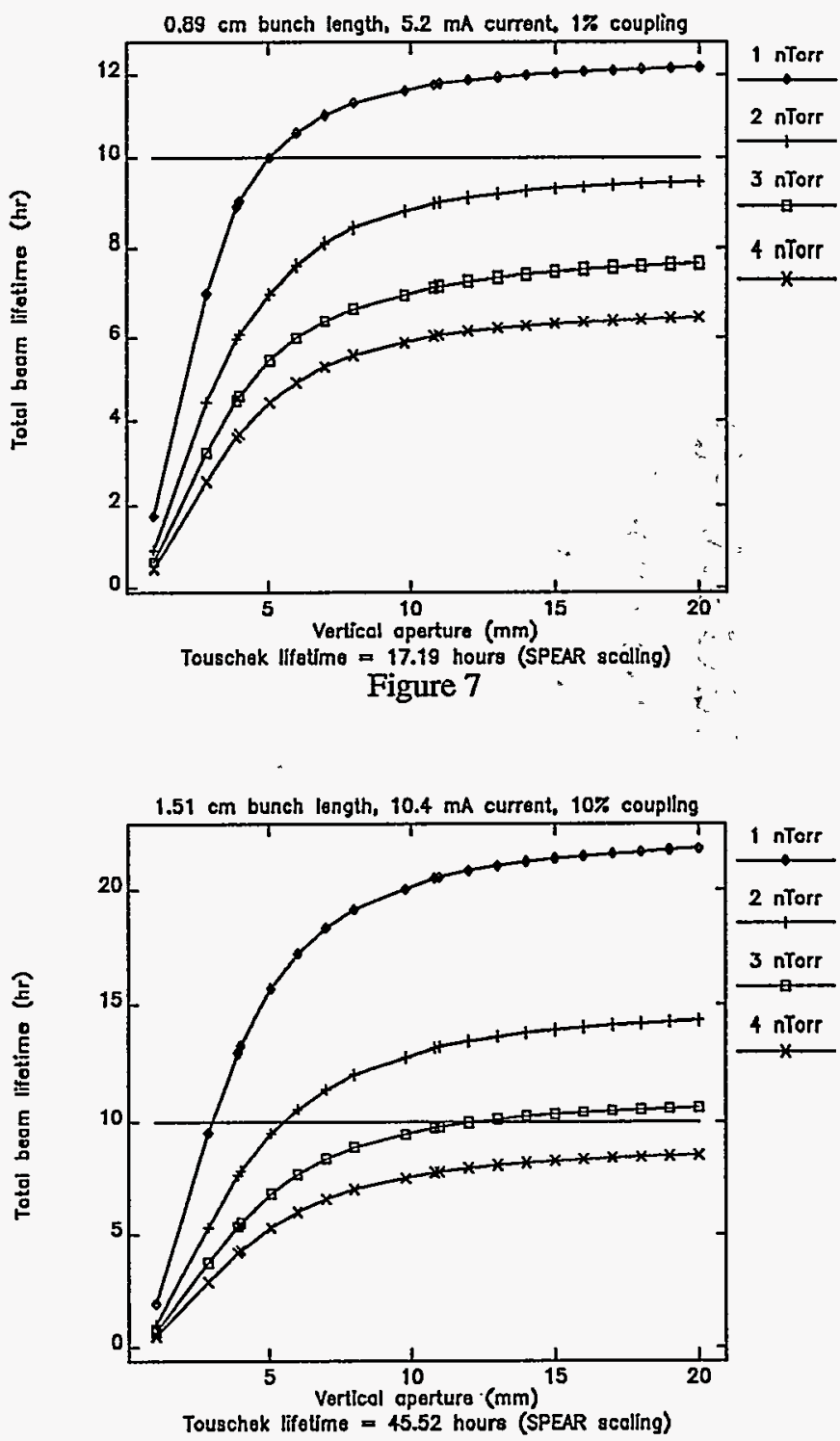

Figure 8

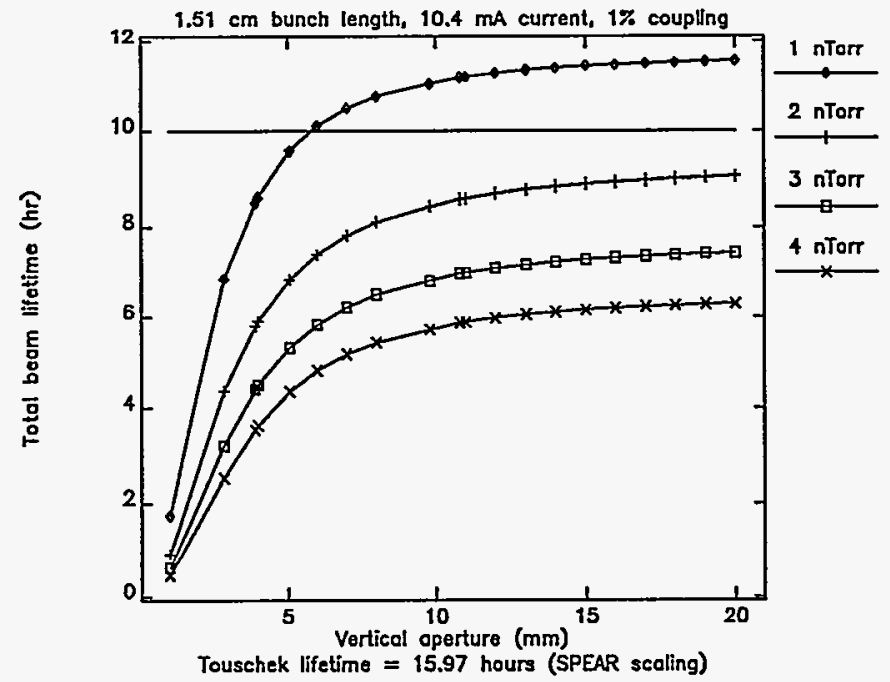

Figure 9 